\title{
Chemical Composition and Nutritional Value of Different Species of Vespa Hornets
}

\author{
Sampat Ghosh ${ }^{1}\left(\mathbb{D}\right.$, Saeed Mahamadzade Namin ${ }^{1,2}$, Victor Benno Meyer-Rochow ${ }^{1,3}$ and Chuleui Jung 1,4, $^{(\mathbb{D}}$ \\ 1 Agriculture Science and Technology Research Institution, Andong National University, Andong 36729, Korea; \\ sampatghosh.bee@gmail.com (S.G.); saeedmn2005@gmail.com (S.M.N.); meyrow@gmail.com (V.B.M.-R.) \\ 2 Department of Plant Protection, College of Agriculture, Varamin-Pishva Branch, Islamic Azad University, \\ Varamin 3381774895, Iran \\ 3 Department of Ecology and Genetics, Oulu University, 90140 Oulu, Finland \\ 4 Department of Plant Medicals, Andong National University, Andong 36729, Korea \\ * Correspondence: cjung@andong.ac.kr; Tel.: +82-54-820-6229
}

Citation: Ghosh, S.; Namin, S.M.;

Meyer-Rochow, V.B.; Jung, C.

Chemical Composition and

Nutritional Value of Different Species of Vespa Hornets. Foods 2021, 10, 418. https://doi.org/10.3390/

foods10020418

Academic Editor: Anthony Fardet

Received: 27 January 2021

Accepted: 11 February 2021

Published: 14 February 2021

Publisher's Note: MDPI stays neutral with regard to jurisdictional claims in published maps and institutional affiliations.

Copyright: (C) 2021 by the authors. Licensee MDPI, Basel, Switzerland. This article is an open access article distributed under the terms and conditions of the Creative Commons Attribution (CC BY) license (https:// creativecommons.org/licenses/by/ $4.0 /)$.
Abstract: We genetically identified three different species of hornets and analyzed the nutrient compositions of their edible brood. Samples were collected from a commercial production unit in Shizong province of China and from forests near Andong City in Korea. The species were identified as Vespa velutina, V. mandarinia, and $V$. basalis from China and $V$. velutina from Korea. Farmed $V$. velutina and $V$. mandarinia were found to have similar protein contents, i.e., total amino acids, whereas $V$. basalis contained less protein. The $V$. velutina brood collected from the forest contained the highest amount of amino acids. Altogether 17 proteinogenic amino acids were detected and quantified with similar patterns of distribution in all three species: leucine followed by tyrosine and lysine being predominant among the essential and glutamic acid among the non-essential amino acids. A different pattern was found for fatty acids: The polyunsaturated fatty acid proportion was highest in $V$. mandarinia and $V$. basalis, but saturated fatty acids dominated in the case of $V$. velutina from two different sources. The high amounts of unsaturated fatty acids in the lipids of the hornets could be expected to exhibit nutritional benefits, including reducing cardiovascular disorders and inflammations. High minerals contents, especially micro minerals such as iron, zinc, and a high $\mathrm{K} / \mathrm{Na}$ ratio in hornets could help mitigate mineral deficiencies among those of the population with inadequate nutrition.

Keywords: Vespa velutina; Vespa mandarinia; Vespa basalis; entomophagy; amino acids; fatty acids; minerals

\section{Introduction}

Numerous communities in the world traditionally include the broods of wasps and hornets (Hymenoptera) in their diets (Figure 1). Since ancient times it has been customary for Chinese people, especially those from Yunnan, to consume wasps, as is documented in a book from the Tang dynasty (618-907 C.E.) [1]. In Korea, Vespa hornet nests and larvae are harvested for medicinal and occasional edible use, especially $V$. mandarinia [2]. In Laos insects including wasps and hornets are consumed by $95 \%$ of the population, with the exception of two provinces for which a value of $85-90 \%$ has been reported [3]. The hornets consumed are of a different species, but $V$. affinis and $V$. tropica are particularly popular in Laos [4], whereas $V$. cincta (synonym to $V$. tropica, based on a report by [5]) is favored in Northern Thailand [6]. Wasp pupae as well as the adults belonging to the genus Vespula, locally known as hebo, are popular in the mountainous region of Honshu, Japan $[7,8]$. People commonly harvest the wasp nest from the forest, but in some cases the wasps are semi-domesticated [4,8] (Figure 1B). 


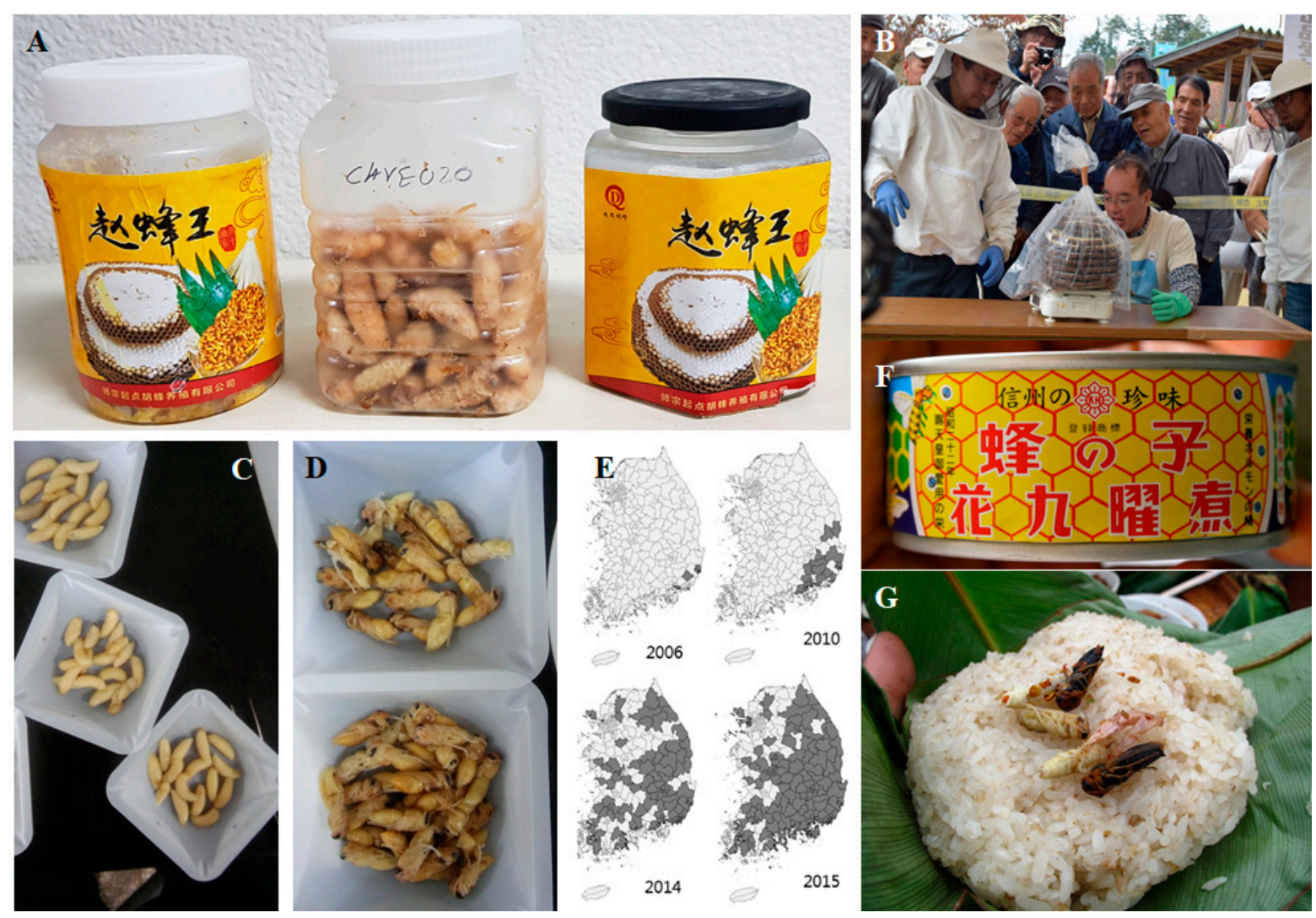

Figure 1. (A) bottled hornet larvae sold in China; (B) hebo (Vespula sp.) contest in which judges evaluate wasp nests by weight in search for the largest nest of domestically raised wasps. [Photo credit: Soleil Ho; source: https://www. splendidtable.org/story / the-japanese-tradition-of-raising-and-eating-wasps, accessed on 31 August 2019]; (C) larvae of Vespa velutina collected from the forest near Andong (Korea); (D) pupae of Vespa velutina collected from the forest near Andong (Korea); (E) range expansion of the invasive hornet Vespa velutina in Korea [Source: 19]; (F) canned hachinoko (wasp brood) in Japan; (G) practice of eating wasps in Yunnan province [Source: http:/ / teaurchin.blogspot.com/2011/10/weirdthings-ive-eaten-in-yunnan.html, accessed on 31 August 2019].

The preparation of the wasp and hornet brood for consumption varies. The most common method of preparation includes deep-frying or frying with chicken eggs as in Yunnan, but the Dai people of southern Yunnan prefer to steam larvae and pupae together and mix them with vinegar and other seasonings [1]. Korean people also prefer frying and roasting [2], whereas Japanese people cook or preserve the wasps using soy sauce and mirin (sweet cooking rice wine) [8]. Although in Korea hornets are not considered a common food, they did, however, feature in the armamentarium of Korean traditional medicine. Polistes and Vespa larvae and adults are used as therapeutics for different ailments $[9,10]$.

Vespa spp. have received attention not only as edible insects, but also as a pest affecting honeybee populations. In this context $V$. velutina, an invasive species, is regarded as the most obnoxious in Korea [11,12] and in Europe as well [13]. Although the Asian honeybee, Apis cerana, has evolved a "heat balling defense" and warning behavior when hornets are patrolling near their nests, the European honeybee, $A$. mellifera, does not possess this behavior and is therefore more susceptible to an attack by $V$. velutina [14-17]. A study of risk prediction in connection with the distribution of $V$. velutina $[18,19]$ shows that the yearly dispersal of the species is $9.4 \mathrm{~km}$ northward in Korea and that this could have a serious impact on beekeeping as well as biodiversity and the ecosystem in general.

Nine native and one invasive hornet species occur in South Korea: V. analis, V. binghami, V. mandarinia, V. simillima simillima, V. simillima xantothorax, V. crabro crobroformis, $V$. crabro flavofasciata, $V$. ducalis, $V$. dybowskii, and $V$. velutina nigrothorax $[20,21]$. The lifecycle of the Vespa species includes different phases. Following overwintering, the emergence 
foundress, i.e., mated queen, searches for a suitable nest site and then constructs the primary nest for egg laying. About a month later, the eggs will have developed into female, non-reproductive adult workers and predation begins. During that time the workers build a secondary nest that is bigger in size than the primary nest. After that, large numbers of future queens are produced, which mate with drones that stem from unfertilized eggs. As the winter approaches, drones and workers die, while queens seek out overwintering places and the cycle continues the following spring [13].

Harvesting these wasps and hornets (Vespa spp.) can be a mode of biocontrol, but it can also lead to the use of these species as human food or animal feed. The present study was undertaken to assess the nutrient composition of three different species of Vespa. It was hoped that an investigation such as this would give us an opportunity to understand why there are differences in amino acid as well as fatty acid compositions between semidomesticated hornets and specimens collected from the wild, e.g., the forest environment.

\section{Materials and Methods}

\subsection{Sample Collection and Preparation}

Three bottles of Vespa broods, representing three species, were obtained in frozen and dried form from a hornet-producing farm in Shizong County in China. The hornets were semi-domesticated primarily to be sold as food. All of the Vespa samples were packed into a freezing box and brought to the laboratory (Andong National University, Andong, South Korea). Samples were stored at $-20{ }^{\circ} \mathrm{C}$ until further processing. A few individuals $(n=10)$ from each bottle were taken for our DNA barcoding experiment in order to identify the species. Specimens used in the chemical analyses were not separated according to developmental stage; they included late instar larvae and pupae together, almost 50:50 (as this is the way they are sold and used by the consumer), but excluded adults.

A V. velutina nest was harvested in early morning from the forest behind the university (Andong City, Korea) in the month of July and brought to the laboratory. The broods were collected, similar to the Chinese commercial late instar larvae and pupae in a 50:50 proportion, separately from the nest and kept in a refrigerator $\left(-20^{\circ} \mathrm{C}\right)$ until further processing $(n=100)$, which involved freeze drying and grinding up into a homogenous powder form.

\subsection{Identification of the Species}

The collected specimens i.e., broods of Vespa, were labelled VEUN20, VENU21, and VENU22 and identified based on DNA barcoding. The total DNA of each sample was extracted from the head and thorax using a DNeasy Blood \& Tissue kit (QIAGEN, Inc., Dusseldorf, Germany) following the manufacturer's protocol. Two primers, LCO-1490 (5'-GGT CAA CAA ATC ATA AAG ATA TTG G-3') and HCO-2198 (5'-TAA ACT TCA GGG TGA CCA AAA AAT CA-3') targeting mitochondrial the Cytochrome Oxidase I (COI) gene [22] were used. The polymerase chain reaction (PCR) was conducted using AccuPower PCR PreMix (Bioneer, Daejeon, Korea) in order to amplify the COI gene corresponding to "DNA Barcode" region [23]. Sequencing was performed commercially by Macrogen (Seoul, South Korea). All three sequences were generated in both directions and assembled using Bioedit v7.0.5.2 [24] to annotate the species level identification using the BLAST (Basic Local Alignment Search Tool) database of the National Center for Biotechnology Information (NCBI) (http:/ / www.ncbi.nlm.nih.gov, accessed on 31 August 2019). Based on the similarity (in \%) the specimens were identified.

\subsection{Nutritional Composition Analyses}

\subsubsection{Amino Acid Analysis}

The amino acid composition was estimated using a Sykam Amino Acid analyzer S433 (Sykam GmbH, Eresing, Germany) following a standard method of AOAC (Association of Official Analytical Chemists) [25]. The Vespa samples in powder form were hydrolyzed in $6 \mathrm{~N} \mathrm{HCl}$ for $24 \mathrm{~h}$ at $110^{\circ} \mathrm{C}$ under a nitrogen atmosphere followed by concentrating in a ro- 
tary evaporator. The concentrated samples were reconstituted with sample dilution buffer provided by the manufacturer $(0.12 \mathrm{~N}$ citrate buffer, $\mathrm{pH} 2.20)$. The hydrolyzed samples were analyzed for amino acid composition. The amino acid score was calculated considering the total estimated amino acid as protein, based on the WHO/FAO/UNU (World Health Organization/Food and Agriculture Organization/United Nations University) [26] report of a joint WHO/FAO/UNU Expert Consultation on protein and amino acid requirements in human nutrition following the formula [27]:

$$
\text { Amino acid score }=\frac{(\mathrm{mg} \text { of amino acid in } 1 \mathrm{~g} \text { of test protein }) \times 100}{\mathrm{mg} \text { of amino acid in reference pattern }}
$$

\subsubsection{Fatty Acid Composition Analysis}

Fatty acid compositions of studied Vespa were determined and quantified using gas chromatography-flame ionization detection (GC-14B, Shimadzu, Tokyo, Japan) equipped with an SP-2560 column, following the recommended method of the Korean Food Standard Codex [28]. Briefly, the samples were derivatized into fatty acid methyl esters (FAMEs), which were then identified and quantified by comparing the retention time and peak areas of standards from Sigma (Yongin, Korea) and analyzed under the same conditions.

\subsubsection{Mineral Analysis}

Minerals of nutritional importance were analyzed following standard procedures of the Korean Food Standard Codex [28]. Dried Vespa powder samples were digested with nitric and hydrochloric acid (1:3) at $200{ }^{\circ} \mathrm{C}$ for $30 \mathrm{~min}$ in a high pressure microwave digestive system. The mineral contents, upon filtration with 0.45 micron filter paper, were analyzed using an inductively coupled plasma-optical emission spectrophotometer (ICP-OES 720 series; Agilent; Santa Clara, CA, USA). Recommended dietary allowance (RDA), population reference intake (PRI), and adequate intake (AI) values for the respective minerals were obtained from organizations such as the Linus Pauling Institute of Oregon State University and the European Food Safety Authority (EFSA).

\subsubsection{Statistical Analysis}

Composite sampling methods were followed including 100 samples for each group. In order to increase reliability the chemical analysis was carried out in at least duplicate and represented as mean \pm standard deviation. To test the differences for individual nutrients of different Vespa, we carried out one-way ANOVA (analysis of variance) followed by a post hoc test (Tukey's Honestly Significant Difference (HSD)) using SPSS 16.0 (SPSS Inc., Chicago, IL, USA). If the $p$-value was found to be $\leq 0.05(\mathrm{CI}=95 \%)$, the null hypothesis was rejected.

\section{Results}

\subsection{Identification of the Species}

With the help of the DNA barcoding method, based on the similarity between the sequences obtained in this study and sequences existing in the NCBI database, we identified the three species, VEUN20 as V. mandarinia, VENU21 as V. basalis, and VENU22 as V. velutina. The obtained sequences for the COI gene, corresponding to the "DNA Barcode" region, are available in GenBank under accession number MN477949- MN477951 (Appendix A).

\subsection{Nutritional Composition of Vespa}

\subsubsection{Amino Acids}

Amino acid compositions of the Vespa species studied are represented in Table 1 . There were 17 amino acids in all Vespa samples. There was a significant difference in the total amino acid content of broods of different species of Vespa $(\mathrm{df}=3,4, \mathrm{~F}=19.135, p=0.008)$. Almost all the amino acids were found to be higher in the $V$. velutina brood collected from the wild in Korea. However, the differences were not significant in all cases (Table 1). 
Considering the totality of the amino acids as protein, the results show that $V$. velutina and $V$. mandarinia collected from the commercial production unit in Shizong province (China) had similar protein contents whereas $V$. basalis contained less protein. However, V. velutina broods collected from the forest near Andong (Korea) contained the highest amount of amino acids. Leucine was the predominating essential amino acid followed by lysine and valine. Tryptophan was not assessed and the amounts of cysteine and methionine were not measured in their entirety presumably because of the acid hydrolysis process [29]. Among the non-essential amino acids, glutamic acid was the most abundant one. The amino acid scoring pattern suggested that among all the estimated indispensable amino acids, methionine was found to be limiting; others satisfied (having a score of $>100$ ) the ideal protein pattern recommended by the WHO/FAO/UNU [26].

\subsubsection{Fatty Acids}

Table 2 represents the fatty acid compositions of the Vespa broods studied. Significant differences were found in the total fatty acid content of broods of different Vespa species $(\mathrm{df}=3,4, \mathrm{~F}=12.255, p=0.017)$. Palmitic acid was the predominating saturated fatty acid; it was followed by stearic acid. Oleic acid was the most abundant monounsaturated fatty acid. However, there was apparently no consistency in the polyunsaturated group. Except for $V$. velutina from China, linoleic acid was always found in abundance among the polyunsaturated fatty acids, although the quantities varied widely (0.55 to $9.49 \mathrm{mg} / 100 \mathrm{~g})$. Overall, the $V$. mandarinia and $V$. basalis broods were found to have the highest proportions of polyunsaturated fatty acids. However, no such difference was found between the saturated and monounsaturated fatty acid contents in these two species. By contrast, the $V$. velutina brood contained a higher amount of saturated fatty acids followed by monounsaturated and polyunsaturated fatty acids.

\subsubsection{Mineral Content}

Table 3 represents the comparative account of mineral contents of the species studied as well as the RDA values of respective elements. Significant differences in the mineral content, except manganese, of broods of different Vespa species were found (calcium: $\mathrm{df}$ $=3,4, \mathrm{~F}=19.994, p=0.007$; magnesium: $\mathrm{df}=3,4, \mathrm{~F}=478.504, p=0.000$; sodium: $\mathrm{df}=3,4$, $\mathrm{F}=161.653, p=0.000$; potassium: $\mathrm{df}=3,4, \mathrm{~F}=56.353, p=0.001$; phosphorus: $\mathrm{df}=3,4$, $\mathrm{F}=42.778, p=0.002$; iron: $\mathrm{df}=3,4, \mathrm{~F}=38.232, p=0.002$; zinc: $\mathrm{df}=3,4, \mathrm{~F}=19.654, p=0.007$; manganese: $\mathrm{df}=3,4, \mathrm{~F}=4.086, p=0.104$; copper: $\mathrm{df}=3,4, \mathrm{~F}=603.414, p=0.000)$. The $V$. velutina brood collected from the wild in Korea was found to have a higher mineral content except for zinc and copper, however, the differences were not always significant. For magnesium, potassium, phosphorus, iron, and manganese, no significant differences were found between $V$. velutina broods from China and Korea. Potassium was the most abundant element. It was followed by phosphorus. Among the microminerals, iron and zinc were found to be dominating. The farmed $V$. velutina brood contained much less sodium than that detected in the wild-collected $V$. velutina brood. The potassium-to-sodium ratio $(\mathrm{K} / \mathrm{Na})$ in the wild $V$. velutina brood was as high as 11.7 , but even higher ratios were noted in the farmed broods of $V$. velutina, V. mandarinia, and V. basalis, namely, 72.3, 13.7, and 45.5 , respectively. It is noteworthy that the wild-collected $V$. velutina brood contained higher amounts of most of the minerals than the farmed hornets. 


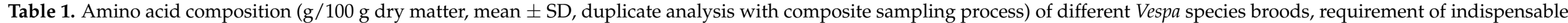
amino acid and amino acid scoring pattern as per the WHO/FAO/UNU [26] and amino acid scoring pattern (\%).

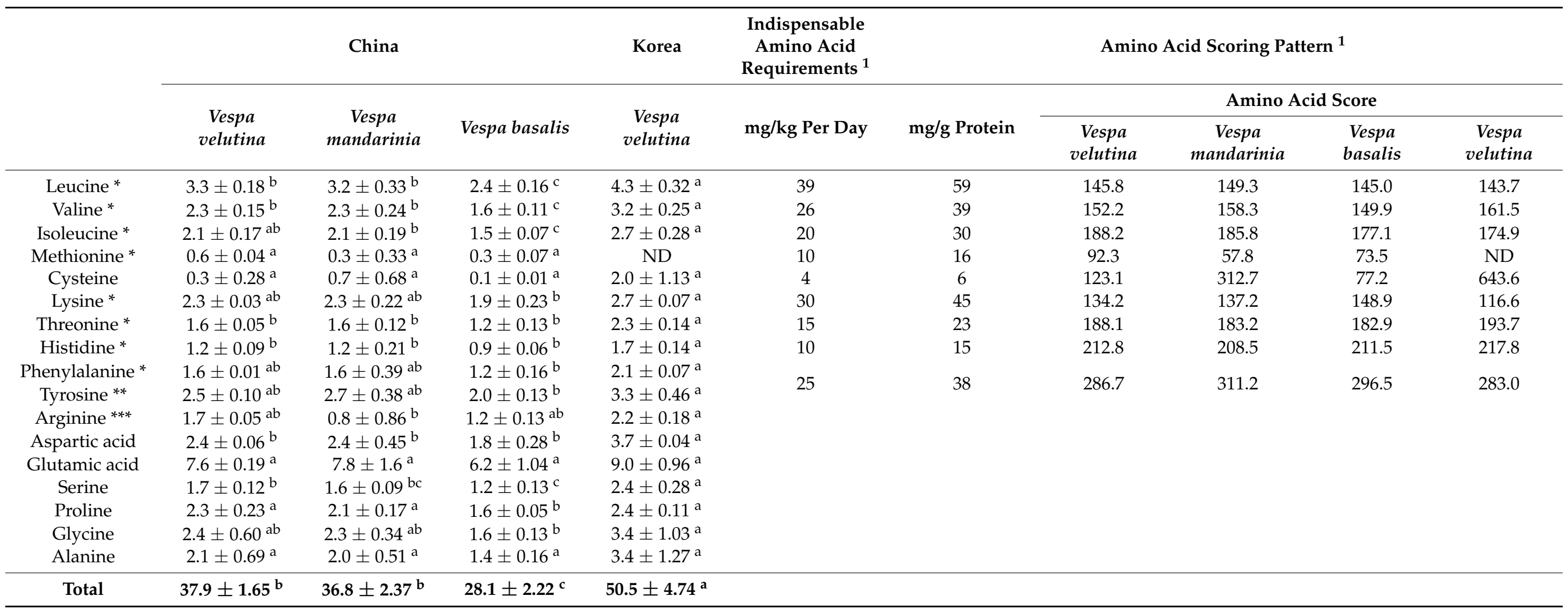

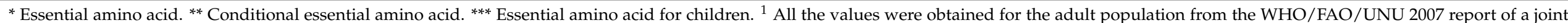
$\mathrm{WHO} / \mathrm{FAO} / \mathrm{UNU}$ Expert Consultation on protein and amino acid requirements in human nutrition. ND $=$ Not detected. Superscripts indicate significant difference ( $p \leq 0.05)$. 
Table 2. Fatty acid composition ( $\mathrm{g} / 100 \mathrm{~g}$ dry matter, mean $\pm \mathrm{SD}$, duplicate analysis with composite sampling process) of different Vespa species broods. Superscripts indicate a significant difference $(p \leq 0.05)$ for selected predominating fatty acids.

\begin{tabular}{|c|c|c|c|c|}
\hline & \multicolumn{3}{|c|}{ China } & \multirow{2}{*}{$\begin{array}{c}\text { Korea } \\
\text { Vespa velutina }\end{array}$} \\
\hline & Vespa velutina & Vespa mandarinia & Vespa basalis & \\
\hline \multicolumn{5}{|c|}{ Saturated Fatty Acids } \\
\hline Capric acid & ND & ND & ND & $<0.01$ \\
\hline Lauric acid & $0.2 \pm 0.04$ & $0.2 \pm 0.04$ & $0.1 \pm 0.02$ & $0.3 \pm 0.02$ \\
\hline Tridecanoic acid & ND & ND & ND & $0.01 \pm 0.00$ \\
\hline Myristic acid & $0.7 \pm 0.14^{\mathrm{a}}$ & $0.5 \pm 0.17^{\mathrm{ab}}$ & $0.3 \pm 0.06^{b}$ & $0.8 \pm 0.11^{\mathrm{a}}$ \\
\hline Palmitic acid & $3.7 \pm 0.49^{a}$ & $4.3 \pm 0.24^{\mathrm{a}}$ & $3.5 \pm 0.01^{\mathrm{a}}$ & $3.5 \pm 0.28^{a}$ \\
\hline Heptadecanoic acid & $0.02 \pm 0.00$ & $0.02 \pm 0.00$ & $0.04 \pm 0.00$ & $0.02 \pm 0.00$ \\
\hline Stearic acid & $0.9 \pm 0.06$ & $1.0 \pm 0.17$ & $1.2 \pm 0.01$ & $0.7 \pm 0.00$ \\
\hline Arachidic acid & $0.1 \pm 0.01$ & $0.2 \pm 0.03$ & $0.2 \pm 0.02$ & $0.1 \pm 0.00$ \\
\hline Behenic acid & ND & $0.1 \pm 0.02$ & $0.1 \pm 0.01$ & $0.1 \pm 0.00$ \\
\hline Lignoceric acid & ND & $0.01 \pm 0.01$ & $0.03 \pm 0.00$ & $0.1 \pm 0.01$ \\
\hline Subtotal & $5.6 \pm 0.71^{a}$ & $6.2 \pm 0.21^{\mathrm{a}}$ & $5.4 \pm 0.05^{\mathrm{a}}$ & $5.4 \pm 0.42^{a}$ \\
\hline \multicolumn{5}{|c|}{ Monounsaturated Fatty Acids } \\
\hline Myristoleic acid & $0.02 \pm 0.01$ & ND & ND & $0.03 \pm 0.01$ \\
\hline Palmitoleic acid & $0.4 \pm 0.10$ & $0.2 \pm 0.05$ & $0.1 \pm 0.00$ & $0.4 \pm 0.06$ \\
\hline cis-10-Heptadecenoic acid & $0.01 \pm 0.02$ & ND & ND & $0.01 \pm 0.00$ \\
\hline Oleic acid & $4.1 \pm 0.44^{b}$ & $5.6 \pm 0.55^{\mathrm{a}}$ & $5.3 \pm 0.29^{a}$ & $4.1 \pm 0.28^{b}$ \\
\hline cis-11-Eocosenic acid & ND & $0.1 \pm 0.06$ & $0.14 \pm 0.027$ & $0.5 \pm 0.01$ \\
\hline Subtotal & $4.6 \pm 0.56^{a}$ & $5.9 \pm 0.56^{a}$ & $5.6 \pm 0.31^{\mathrm{a}}$ & $5.1 \pm 0.37^{\mathrm{a}}$ \\
\hline \multicolumn{5}{|c|}{ Polyunsaturated Fatty Acids } \\
\hline Linoleic acid & $0.6 \pm 0.11^{b}$ & $6.8 \pm 3.09^{a}$ & $9.5 \pm 1.96^{\mathrm{a}}$ & $0.6 \pm 0.02^{b}$ \\
\hline Linolenic acid & $0.8 \pm 0.11$ & $1.2 \pm 0.30$ & $1.8 \pm 0.01$ & ND \\
\hline Arachidonic acid & $0.04 \pm 0.03$ & ND & ND & $0.02 \pm 0.00$ \\
\hline $\begin{array}{c}\text { cis-5,8,11,14,17- } \\
\text { Eicosapentaenoic acid }\end{array}$ & $0.03 \pm 0.02$ & ND & ND & ND \\
\hline Subtotal & $1.4 \pm 0.05^{b}$ & $8.1 \pm 3.39^{a}$ & $11.2 \pm 1.98^{a}$ & $0.6 \pm 0.04^{b}$ \\
\hline Total & $11.5 \pm 1.31^{b}$ & $20.1 \pm 3.75^{a}$ & $22.2 \pm 2.25^{\mathrm{a}}$ & $11.1 \pm 0.82^{b}$ \\
\hline
\end{tabular}




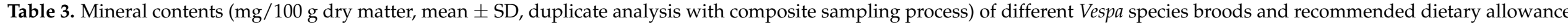
(RDA) or population reference intakes (PRI) and satisfying the requirement in \%

\begin{tabular}{|c|c|c|c|c|c|c|c|c|c|c|c|c|c|c|c|c|}
\hline & \multicolumn{3}{|c|}{ China } & & \multicolumn{2}{|c|}{ RDA $^{1}$} & \multicolumn{2}{|c|}{ PRI/AI ${ }^{2}$} & \multicolumn{8}{|c|}{$\begin{array}{l}\text { Satisfying the Requirement as per PRI/AI }{ }^{2} \text { by } 100 \mathrm{~g} \text { of Consumption of } \\
\text { Respective Vespa Brood (in \%) }{ }^{3}\end{array}$} \\
\hline & \multirow[b]{2}{*}{$\begin{array}{c}\text { Vespa } \\
\text { velutina }\end{array}$} & \multirow[b]{2}{*}{$\begin{array}{l}\text { Vespa } \\
\text { mandarinia }\end{array}$} & \multirow[b]{2}{*}{ Vespa basalis } & & \multirow[b]{2}{*}{$\mathbf{M}$} & \multirow[b]{2}{*}{$\mathbf{F}$} & \multirow[b]{2}{*}{$\mathbf{M}$} & \multirow[b]{2}{*}{$\mathbf{F}$} & \multicolumn{2}{|c|}{ Vespa velutina } & \multicolumn{2}{|c|}{ Vespa mandarinia } & \multicolumn{2}{|c|}{ Vespa basalis } & \multicolumn{2}{|c|}{ Vespa velutina } \\
\hline & & & & Vespa velutina & & & & & $\mathbf{M}$ & $\mathbf{F}$ & $\mathbf{M}$ & $\mathbf{F}$ & $\mathbf{M}$ & $\mathbf{F}$ & $\mathbf{M}$ & $\mathbf{F}$ \\
\hline $\mathrm{Ca}$ & $38.8 \pm 0.04^{\mathrm{b}}$ & $27.4 \pm 0.20^{\mathrm{c}}$ & $31.8 \pm 0.34^{b c}$ & $46.3 \pm 5.22^{a}$ & \multicolumn{2}{|c|}{1000} & \multicolumn{2}{|c|}{950} & \multicolumn{2}{|c|}{4.1} & \multicolumn{2}{|c|}{2.9} & \multicolumn{2}{|c|}{3.3} & \multicolumn{2}{|c|}{4.9} \\
\hline $\mathrm{Mg}$ & $63.9 \pm 0.01^{\mathrm{a}}$ & $33.0 \pm 0.44^{\mathrm{c}}$ & $38.2 \pm 0.24^{b}$ & $66.3 \pm 2.16^{a}$ & 400 & 310 & $350^{+}$ & $300^{+}$ & 18.3 & 21.3 & 9.4 & 11.0 & 10.9 & 12.7 & 18.9 & 22.1 \\
\hline $\mathrm{Na}$ & $10.4 \pm 0.02^{c}$ & $30.8 \pm 0.40^{b}$ & $8.9 \pm 0.09^{c}$ & $61.5 \pm 5.44^{\mathrm{a}}$ & 1500 * & $3800 *$ & - & - & 0.7 & 0.3 & 2.1 & 0.8 & 0.6 & 0.2 & 4.1 & 1.6 \\
\hline $\mathbf{K}$ & $751.6 \pm 0.87^{a}$ & $422.7 \pm 6.58^{b}$ & $404.4 \pm 0.01^{b}$ & $718.6 \pm 69.87^{a}$ & $3400 *$ & $2600 *$ & \multicolumn{2}{|c|}{$3500^{+}$} & \multicolumn{2}{|c|}{21.5} & \multicolumn{2}{|c|}{12.1} & \multicolumn{2}{|c|}{11.6} & \multicolumn{2}{|c|}{20.5} \\
\hline $\mathbf{P}$ & $561.2 \pm 1.18^{a}$ & $322.5 \pm 2.93^{b}$ & $318.4 \pm 4.90^{\mathrm{b}}$ & $641.9 \pm 71.37^{a}$ & \multicolumn{2}{|c|}{700} & \multicolumn{2}{|c|}{$550^{+}$} & \multicolumn{2}{|c|}{102.0} & \multicolumn{2}{|c|}{58.6} & \multicolumn{2}{|c|}{57.9} & \multicolumn{2}{|c|}{116.7} \\
\hline $\mathrm{Fe}$ & $10.0 \pm 0.12^{\mathrm{a}}$ & $7.2 \pm 0.41^{b}$ & $5.0 \pm 0.18^{c}$ & $9.1 \pm 0.89^{a}$ & 8 & 18 & 11 & 16 & 90.9 & 62.5 & 65.5 & 45.0 & 45.5 & 31.3 & 82.7 & 56.9 \\
\hline $\mathrm{Zn}$ & $7.2 \pm 0.02^{a}$ & $4.7 \pm 0.01^{\mathrm{c}}$ & $5.1 \pm 0.04^{c}$ & $6.1 \pm 0.71^{b}$ & 11 & 8 & 9.4 & 7.5 & 76.6 & 96.0 & 50.0 & 62.7 & 54.3 & 68.0 & 64.9 & 81.3 \\
\hline Mn & $0.6 \pm 0.02^{a b}$ & $0.1 \pm 0.01^{\mathrm{b}}$ & $1.2 \pm 0.68^{a b}$ & $2.8 \pm 1.49^{a}$ & $2.3 *$ & $1.8^{*}$ & \multicolumn{2}{|c|}{$3^{+}$} & & & & & & & & \\
\hline $\mathrm{Cu}$ & $2.2 \pm 0.04^{\mathrm{a}}$ & $0.9 \pm 0.01^{\mathrm{d}}$ & $1.1 \pm 0.04^{c}$ & $1.3 \pm 0.04^{b}$ & & & $1.6^{+}$ & $1.3^{+}$ & 137.5 & 169.2 & 56.3 & 69.2 & 68.8 & 84.6 & 81.3 & 100.0 \\
\hline
\end{tabular}

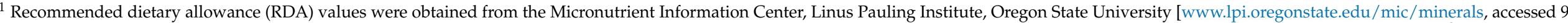

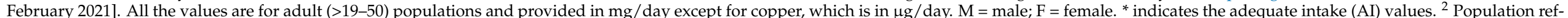

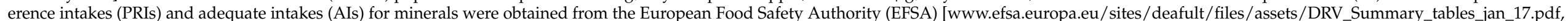

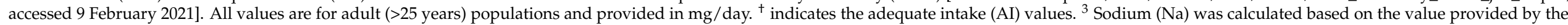
Linus Pauling Institute, Oregon State University; all others were based on values provided by the European Food Safety Authority (EFSA). Superscripts indicate significant difference ( $p \leq 0.05)$. 


\section{Discussion}

\subsection{Amino Acid Composition}

The amino acid distributions seen in our study are in general agreement with a previously published report, although the contents of some of the amino acids in the current study were a little less than what was reported earlier [1]. The total amino acid content as protein content of Vespa broods is comparable with other reports on edible insects, including wasps (V. velutina nigrithorax: 48.64 [30], V. mandarinia: 59.7 [2], V. basalis: 43.91, V. mandarinia: 52.20, V. velutina auraria: 49.03, V. tropica ducalis: 42.44 [1]). In the earlier study, as with ours, overall glutamic acid was the most abundant amino acid. Glutamic acid is the precursor of GABA (gamma aminobutyric acid), which is a neurotransmitter of inhibitory neurons [31] and thus might be responsible for docile behavior. However, the saliva of Vespa spp. larvae is not rich in glutamic acid [32], which could be a reason for the wasps' aggressiveness in defense and times of hunting prey. This aggressive behavior lessens in the nest where trophallaxis is performed, an essential behavioral trait for a social insect. The high proline content, amongst other effects, influences the flight of the insect, because it is metabolized to produce energy for the wing movements during flight [33]. It has been reported that hornet, with higher proline content in their saliva, generally build their nests higher up and also have a wider hunting range than hornets with less proline content in saliva and those live underground or nest in caves or tree holes and hunt over a smaller area [32].

Although $V$. mandarinia and $V$. velutina inhabit subterranean and open-air nests, respectively [34,35], they did not differ with respect to proline content, at least in the brood stage. Nonetheless, differences in body composition can be expected to exist between larvae, pupae, and adults as well as drones, workers, and queens with regard to developmental as well as physiological states, as has been demonstrated for the honeybee (A. mellifera) and the bumblebee (Bombus terrestris) [36-39]. Histidine, decarboxylated to histamine, is a major component of the venom and found in similar amounts in $V$. velutina and $V$. mandarinia, but less in the case of $V$. basalis. Among the indispensable amino acids, leucine was found to predominate and to be present in higher amounts in V. velutina and V. mandarinia than in $V$. basalis. Leucine and isoleucine are metabolized in the musculature.

From a nutritional standpoint, lysine deserves consideration as it is a limiting amino acid in cereals such as rice, wheat, and maize. Catabolism of lysine, an entirely ketogenic amino acid, includes the saccharopine pathway, which results in the formation of glutamate and $\alpha$-aminoadipate. In addition, lysine is also a precursor for the biosynthesis of carnitine, which plays an important role in $\beta$-oxidation [40]. The aromatic amino acid tyrosine functions as precursor of catecholamines such as dopamine, norepinephrine, and epinephrine and is involved in melanogenesis. Tyrosine is a conditionally essential amino acid with phenylalanine playing a crucial role in tyrosine synthesis. Therefore, because of the presence of almost all proteinogenic amino acids and estimated indispensable ones except for methionine, satisfying the recommended protein pattern (Table 1), Vespa broods would supplement the nutritional requirements in people.

\subsection{Fatty Acid Composition}

The higher polyunsaturated acid contents of $V$. mandarinia and $V$. basalis are likely due to their diet, which consists of crickets and grasshoppers, which are often rich in polyunsaturated fatty acids (cf., grasshopper, Chondacris rosea: [41], and crickets, Gryllus sp. and Teleogryllus sp.: [42]). Compared to earlier analyses, the proportions of monounsaturated fatty acids were higher in the case of other hymenopteran species such as, to mention but a few, B. ignitus [37], B. terrestris [38], Carebara vidua [43], Polyrhachis vicina [44,45], and Oecophylla smaragdina [46]. However, diet manipulations can result in changes in the fatty acid composition in farmed versus wild insects [47,48].

Oleic acid was the dominant monounsaturated and palmitic acid, with stearic and myristic acids being the abundant saturated fatty acids. Linoleic acid was the most abundant polyunsaturated fatty acid followed by linolenic acid in $V$. mandarinia and $V$. basalis. 
Primarily saturated fatty acids such as myristic, palmitic, and lauric acids increased the level of low density lipoprotein, the so-called bad cholesterol. However, stearic acid does not raise serum cholesterol [49]. Oleic acid inhibits the store-operated $\mathrm{Ca}^{+2}$ entry process (SOCE) that controls the $\mathrm{Ca}^{+2}$ influx pathway and is involved in several cellular and physiological processes, including cell proliferations that are often diagnostic for colorectal cancer [50]. Oleic acid also shows significant in vitro inhibition of prolyl-endopeptidase (PEP), an enzyme playing a crucial role in the formation of amyloid in the brain and implicated in disorders such as dementia and Alzheimer's disease [50].

Unsaturated fatty acids are being given special attention as they are seen to be beneficial to human health. Earlier studies, e.g., by Grundy [51], demonstrated the capacity of monounsaturated fatty acids to lower lipoprotein density and thus total cholesterol. Polyunsaturated fatty acids play a crucial role in the biosynthesis of cellular hormones such as eicosanoids and other signaling compounds that modulate human health [50]. Polyunsaturated fatty acids are of two types, i.e., $n-6$ and $n-3$, based on the position of the first unsaturated site in the chain. A higher ratio of $n-3$ to $n-6$, i.e., more $n-3$ and less $n-6$ in the diet, is preferable in connection with human health as it helps to reduce weight through the removal of intra-abdominal fat, a drop in adipocyte cell size, and the normalization of the heartbeat. Diets with high $n-3$ polyunsaturated fatty acids enhance the body's ability to reduce damaging inflammatory conditions, as they are usually converted into anti-inflammatory eicosanoids. Besides, epidemiological as well as clinical studies further suggest that $n-3$ polyunsaturated fatty acids, including $n-3$ from marine food resources, help lower cardiovascular mortality [52,53] through mechanisms that include the modulation of cellular metabolic functions and gene expression and exert beneficial effects on lipid profiles and blood pressure [54]. Thus, the presence of linolenic acid in $V$. mandarinia and $V$. basalis could have nutritional benefits for sufferers of cardiovascular complexities.

\subsection{Mineral Content}

Minerals are essential micronutrients that play critical roles in human health. Among the minerals of nutritional importance, potassium was found in abundance followed by phosphorus. The values were within the range of reports on Hymenoptera as well as edible insects belonging to other orders [42,55]. A substantial amount of evidence shows that potassium intake lowers blood pressure. An increased intake of potassium also plays a critical role in the management of hypercalciuria and is likely to decrease the risk of osteoporosis [56]. Low serum potassium is strongly related to glucose intolerance and increases the risk of lethal ventricular arrhythmias in patients suffering from ischemic heart disease. On the other hand, a high intake of dietary sodium is associated with a prevalence of hypertension [57].

From the human nutritional point of view, a high potassium-to-sodium ratio can be regarded as beneficial as it reduces cardiovascular risk and improves blood pressure [58]. All the hornet broods contained higher potassium and comparatively less sodium, and thus can be regarded as beneficial for human health. The calcium content of the Vespa brood was found to be within the range of other insects [55], but less than what had been reported for $A$. mellifera larvae and pupae [36]. Over $99 \%$ of total body calcium by virtue of its phosphate salt is present in the teeth and bones of mammals and the remainder is present in the blood, extracellular fluid, muscle, and other tissues. Calcium plays critical physiological roles, including mediating vascular contraction and vasodilation, muscle contraction, nerve transmission, and glandular secretion, to mention a few [59]. Chronic calcium deficiency often results in a reduction in bone mass and osteoporosis [60], the development of hypertension, and even colon cancer [61].

Among the minerals of nutritional importance, iron receives the most attention. Iron deficiency and anemia still exist and are major public health concerns worldwide, especially in many developing and low-income countries [62,63]. The most vulnerable sections of the population in developing countries regarding iron deficiency are women of childbearing age and children under five $[64,65]$. Although the iron content of the studied species was 
a little less than that was reported for A. mellifera workers [36], it could still supplement the iron requirement, especially for those in the population who cannot afford iron-rich food such as red meat, liver, fish, etc. The element zinc plays a role in several cellular processes, including catalytic, structural, and regulatory roles in many enzymes, gene transcription, signal transduction pathways, etc. [66]. Although severe zinc deficiency is considered rare [67], mild to moderate zinc deficiencies persist worldwide [68]. An inadequate dietary zinc intake is particularly common in Sub-Saharan Africa and South Asia [69]. Based on the RDA values provided by agencies, consumption of $100 \mathrm{~g}$ of Vespa brood could satisfy a significant proportion of daily dietary requirements for minerals, especially iron, zinc, and copper (Table 3). Even if it cannot meet the total mineral need, assuming good bioavailability, the consumption of Vespa brood could at least supplement the nutritional requirements of minerals and could help mitigate the problems of mineral deficiencies in those sections of the population most at risk for them.

\section{Conclusions}

Since it was first suggested in 1975 that insects could help ease the problem of global food shortages [70], the last two decades in particular have seen a remarkable increase in attention to edible insects as a nutrient-rich and healthy food resource. Numerous countries have formulated or are in the process of formulating legislation to regulate mass production and trade of edible insects. The global market value of edible insects is expected to exceed USD 522 million by 2023 [71]. Since 2012, the South Korean edibleinsect market focusing on human consumption alone (not including insects as animal feed) has experienced major advances, with governmental support and successful research endeavors [42,72]. The country's tradition of using certain insects such as processed silkworm pupae, commonly known as beondaegi, as food [73] has further helped. Noting the competent nutrient composition of all three Vespa species examined by us and the feasibility of rearing these insects, we propose that these hornet broods can be a sustainable, high-quality nutritional source. However, the rearing process is yet to be established before any large-scale controlled production can commence.

Author Contributions: Conceptualization, C.J. and S.G.; methodology, S.G. and S.M.N.; software, S.G.; validation, S.G. and S.M.N.; formal analysis, S.G., S.M.N., and C.J.; investigation, S.G., C.J., and S.M.N.; data curation, C.J.; writing-original draft preparation, S.G.; writing-review and editing, C.J., V.B.M.-R., S.G., and S.M.N.; visualization, C.J.; supervision, C.J.; project administration, C.J.; funding acquisition, C.J. All authors have read and agreed to the published version of the manuscript.

Funding: This work was funded by the BSRP through the National Research Foundation of Korea (NRF), Ministry of Education (NRF-2018R1A6A1A03024862).

Institutional Review Board Statement: Not applicable.

Informed Consent Statement: Not applicable.

Data Availability Statement: Not applicable.

Acknowledgments: We appreciate Zhao Quanghui, owner of the Vespa farm in Shizong County and Professor Ken Tan, Chinese Academy of Science, Yunnan province, China, for the valuable assistance on this work. This study was partly supported by the BSRP through the National Research Foundation of Korea (NRF), Ministry of Education (NRF-2018R1A6A1A03024862).

Conflicts of Interest: The authors declare no conflict of interest. 


\section{Appendix A}

Table A1. DNA sequences for the COI gene corresponding to the "DNA Barcode" region of VEUN20 as Vespa mandarinia, VENU21 as Vespa basalis, and VENU22 as Vespa velutina.

\begin{tabular}{|c|c|c|}
\hline ID & Accession No. & Sequence \\
\hline VEUN20 & MN477949 & $\begin{array}{l}\text { TATATTATATTTTATTTTTGCCTTATGATCAGGAACTATCGGAGCATCCATAAGATTAA } \\
\text { TTATTCGAATAGAGCTTAGATCTCCTGGCAATCTAATTAATAATGACCAAATTTACAA } \\
\text { TTCTATTATTACTGCTCACGCATTTATTATAATTTTTTTTATAGTTATACCCTTTATAATT } \\
\text { GGAGGGTTTGGAAATTGATTAATTCCATTAATACTAGGTATTCCAGATATGGCATTTC } \\
\text { CTCGAATAAATAATATAAGATTTTGACTTCTACCTCCTTCATTATTCCTTCTAATTATAA } \\
\text { GAAACTTTATTGGAGGGGGTGTTGGTACAGGATGAACCCTTTATCCCCCCTATCATC } \\
\text { CATTATTGGCCATAATTCTCCTTCAGTAGATCTAAGAATTTTCTCTCTCCATATTGCAGG } \\
\text { AATTTCTTCAATTATAGGAGCAATTAATTTTATTGTAACAATTCTAAATATACATGTCAAA } \\
\text { ACCCATTCATTAAATTTTTTACCATTATTCTCTTGGTCTGTCCTAATTACAGCATTCTTATT } \\
\text { ACTTTTATCTTTACCTGTTTTAGCTGGCGCAATCACCATACTTTTAACAGATCGAAATTTT } \\
\text { AATACATCCTTTTTCGATCCAACTGGAGGCGGAGACCCCATCTTATACCAACATTTATTC }\end{array}$ \\
\hline VEUN21 & MN477950 & $\begin{array}{l}\text { AATACTTTATTTTATTTTTGCTTTATGATCAGGATCTTTAGGAGCCTCTATAAGTTTAA } \\
\text { TTATTCGTATAGAACTTAGATCCCCAGGAAGATTAATTAACAACGATCAAATCTATAAT } \\
\text { TCTATTATTACCGCTCATGCTTTTATTATAATTTTTTTTATAGTTATACCTTTTATAATTG } \\
\text { GAGGATTTGGAAATTGATTAATTCCTTTAATATTAGGAATTCCAGATATAGCTTTTCCT } \\
\text { CGAATAAATAATATAAGATTCTGACTATTACCTCCCTCTTTATTTCTATTAATTATAAGAA } \\
\text { ATTTTATTGGAGGAGGAGTAGGAACTGGATGAACTCTTTACCCACCTCTATCATCAATT } \\
\text { ACTGGTCATAATTCTCCAGCTGTTGATCTTAGAATCTTTTCATTACATATTGCAGGAATT } \\
\text { TCATCAATTATAGGAGCCATTAATTTCATTGTTACAATTTTAAACATACACATTAAAACT } \\
\text { CACTCACTAAGATTCTTACCTTTATTTTCATGATCAGTTTTAATTACAGCATTTTTACTAT } \\
\text { TATTATCCTTACCTGTTCTAGCAGGAGCAATTACAATACTTCTTACCGATCGAAACTTTA } \\
\text { ATACATCATTTTTTGATCCCACAGGAGGAGGAGACCCTATTTTATATCAACATTTATTT }\end{array}$ \\
\hline VEUN22 & MN477951 & $\begin{array}{l}\text { AATATTATACTTTATTTTTGCATTATGATCTGGAACATTGGGAGCATCAATAAGATTAA } \\
\text { TTATTCGTATAGAATTAAGATCTCCCGGAAATTTAATTAATAATGATCAAATTTATAATT } \\
\text { CAATTATCACTGCTCATGCTTTTATTATAATTTTTTTTATAGTTATACCTTTTATAATCGG } \\
\text { AGGATTCGGTAACTGAATAATTCCTCTAATACTCGGAATTCCTGATATAGCTTTCCCTC } \\
\text { GAATAAATAATATAAGATTCTGACTACTCCCTCCATCATTATTTATATTAATTATAAGAA } \\
\text { ACTTTATTGGTGGAGGTGTAGGAACAGGATGAACTTTATATCCTCCTTTATCATCAATT } \\
\text { ACTGGTCATAACTCACCATCAGTTGATTTAAGAATTTTCTCTTTACATATTGCAGGAAT } \\
\text { TTCATCAATTATAGGTGCAATTAATTTTATTGTAACAATTCTGAATATACATGTAAAAAC } \\
\text { ACACTCATTAAATTTTTACCATTATTCTCATGATCAGTCTTAATTACTGCTTTTTTACTT } \\
\text { TTATTATCACTCCCTGTATTAGCAGGAGCTATTACTATACTTTTAACAGATCGAAATTTTA } \\
\text { ATACATCATTCTTCGATCCAACCGGAGGAGGAGACCCAATTCTATATCAACACTTATTT }\end{array}$ \\
\hline
\end{tabular}

\section{References}

1. Ying, F.; Xiaoming, C.; Long, S.; Zhiyong, C. Common edible wasps in Yunnan Province, China and their nutritional value. In Forest Insects as Food: Human Bites Back; Durst, P.B., Johnson, D.V., Leslie, R.N., Shono, K., Eds.; Food and Agriculture Organi-zation of the United Nations; Regional Office for Asia and the Pacific: Bangkok, Thailand, 2010; pp. 93-98.

2. Kim, H.S.; Jung, C. Nutritional characteristics of edible insects as potential food materials. Korean J. Apic. 2013, $28,1-8$.

3. Barennes, H.; Phimmasane, M.; Rajaonarivo, C. Insect Consumption to Address Undernutrition, a National Survey on the Prevalence of Insect Consumption among Adults and Vendors in Laos. PLoS ONE 2015, 10, e0136458. [CrossRef]

4. Hanboonsong, Y.; Durst, P.B. Edible Insects in Lao PDR: Building on Tradition to Enhance Food Security; Food and Agriculture Organization of the United Nations-Regional Office for Asia and the Pacific: Bangkok, Thailand, 2014.

5. Carpenter, J.M.; Kojima, J. Checklist of the species in the subfamily Vespinae (Insects: Hymenoptera: Vespinae). Nat. Hist. Bull. Ibaraki Univ. 1997, 1, 51-92.

6. Leksawasdi, P. Compendium of research on selected edible insects in northern Thailand. In Forest Insects as Food: Human Bites Back; Durst, P.B., Johnson, D.V., Leslie, R.N., Shono, K., Eds.; Food and Agriculture Organization of the United Nations-Regional Office for Asia and the Pacific: Bangkok, Thailand, 2010; pp. 183-188.

7. Nonaka, K. Feasting on insects. Ėntomol. Res. 2009, 39, 304-312. [CrossRef]

8. Payne, C.L.R.; Evans, J.D. Nested Houses: Domestication dynamics of human-wasp relations in contemporary rural Japan. J. Ethnobiol. Ethnomedicine 2017, 13, 13. [CrossRef]

9. Pemberton, R.W. Insects and other arthropods used as drugs in Korean traditional medicine. J. Ethnopharmacol. 1999, 65, 207-216. [CrossRef] 
10. Meyer-Rochow, V.B. Therapeutic arthropods and other largely terrestrial folk-medicinally important invertebrates: A comparative survey and review. J. Ethnobiol. Ethnomedicine 2017, 13, 9. [CrossRef] [PubMed]

11. Jung, C.; Kim, D.W.; Lee, H.S.; Baek, H. Some Biological Characteristics of a New Honeybee Pest, Vespa velutina nigrithorax Buysson, 1905 (Hymenoptera: Vespidae). Korean J. Apic. 2009, 24, 61-65.

12. Jung, C. Initial state risk assessment of an invasive hornet, Vespa velutina nigrithorax Buysson (Hymenoptera: Vespidae) in Korea. Korean J. Apic. 2012, 27, 95-104.

13. Monceau, K.; Bonnard, O.; Thiéry, D. Vespa velutina: A new invasive predator of honeybees in Europe. J. Pest Sci. 2014, 87, 1-16. [CrossRef]

14. Shah, F.A.; Shah, T.A. Vespa Velutina, a Serious Pest of Honey Bees in Kashmir. Bee World 1991, 72, 161-164. [CrossRef]

15. Abrol, D.P. Ecology, behaviour and management of social wasp, Vespa velutina Smith (Hymenoptera: Vespidae), attacking honeybee colonies. Korean J. Apic. 1994, 9, 5-10.

16. Tan, K.; Radloff, S.E.; Li, J.J.; Hepburn, H.R.; Yang, M.X.; Zhang, L.J.; Neumann, P. Bee-hawking by the wasp, Vespa velutina, on the honeybees Apis cerana and A. mellifera. Naturwissenschaften 2007, 94, 469-472. [CrossRef] [PubMed]

17. Ono, M.; Okada, I.; Sasaki, M. Heat production by balling in the Japanese honeybee, Apis cerana japonica as a defensive behavior against the hornet Vespa simillima xanthoptera (Hymenoptera: Vespidae). Cell. Mol. Life Sci. 1987, 43, 1031-1034. [CrossRef]

18. Jung, C. Spatial expansion of an invasive hornet, Vespa velutina nigrithorax Buysson (Hymenoptera: Vespidae) in Korea. Korean J. Apic. 2012, 27, 87-93.

19. Park, J.-J.; Jung, C. Risk Prediction of the Distribution of Invasive Hornet, Vespa velutina nigrothorax in Korea using CLIMEX Model. J. Apic. 2016, 31, 293-303. [CrossRef]

20. Jung, C.; Kang, M.S.; Kim, D.W.; Lee, H.S. Vespid Wasps (Hymenoptera) Occurring Around Apiaries in Andong, Korea-I. Taxonomy and life history. Korean J. Apic. 2007, 22, 53-62.

21. Choi, M.B.; Kim, J.K.; Lee, J.W. Checklist and Distribution of Korean Vespidae Revisited. Korean J. Appl. Èntomol. 2013, 52, 85-91. [CrossRef]

22. Folmer, O.; Black, M.; Hoeh, W.; Lutz, R.; Vrijenhoek, R. DNA primers for amplification of mitochondrial cytochrome c oxidase subunit I from diverse metazoan invertebrates. Mol. Mar. Biol. Biotechnol. 1994, 3, 294-299.

23. Hebert, P.D.; Ratnasingham, S.; de Waard, J.R. Barcoding animal life: Cytochrome c oxidase subunit 1 divergences among closely related species. Proc. R. Soc. B Biol. Sci. 2003, 270, S96-S99. [CrossRef]

24. Hall, T.A. BioEdit: A user-friendly biological sequence alignment editor and analysis program for Windows 95/98/NT. Nucleic Acids Symp. 1999, 41, 95-98.

25. AOAC. Official Methods of Analysis of the AOAC, 15th ed.; Association of official analytical chemists: Washington, DC, USA, 1990.

26. FAO/WHO/UNU. Protein and Amino Acid Requirements in Human Nutrition, Report of a FAO/WHO/UNU Expert Consultation; WHO Technical Report Series no. 935; World Health Organisation: Geneva, Switzerland, 2007.

27. Millward, D.J. Amino acid scoring patterns for protein quality assessment. Br. J. Nutr. 2012, 108, S31-S43. [CrossRef]

28. Ministry of Food and Drug Safety. Korean Food Standard Codex; Ministry of Food and Drug Safety: Cheongju, Korea, 2010.

29. Pickering, M.V.; Newton, P. Amino acid hydrolysis: Old problems, new solutions. Lc Gc 1990, 8, 778-781.

30. Jeong, H.; Kim, J.M.; Kim, B.; Nam, J.-O.; Hahn, D.; Choi, M.B. Nutritional Value of the Larvae of the Alien Invasive Wasp Vespa velutina nigrithorax and Amino Acid Composition of the Larval Saliva. Foods 2020, 9, 885. [CrossRef] [PubMed]

31. Curtis, C.R.; Watkins, J.C. The pharmacology of amino acids related to gamma-aminobutyric acid. Pharmacol. Rev. 1965, 17, 347-391.

32. Abe, T.; Tanaka, Y.; Miyazaki, H.; Kawasaki, Y.Y. Comparative study of the composition of hornet larval saliva, its effect on bahviour and role of trophallaxis. Comp. Biochem. Physiol. Part C Comp. Pharmacol. 1991, 99C, 79-84.

33. Beenakkers, A.M.T.; Horst, D.J.V.; Marrewijk, J.A.V. Biochemical process directed to flight muscle metabolism. In Comprehensive Insect Physiology, Biochemistry and Pharmacology; Kerkut, G.A., Gilbert, L.I., Eds.; Pergamon Press: Oxford, UK, 1985; Volume 10, pp. 451-486.

34. Matsuura, M.; Sakagami, S.F. A bionomic sketch of the giant hornet, Vespa mandarinia, a serious pest for Japanese apiculture. J. Fac. Sci. Hokkaido Univ. Ser. VI Zoo. 1973, 19, 125-162.

35. Sánchez, X.F.; Charles, R.J. Notes on the nest-architecture and colony composition in winter of the Yellow-legged Asian hornet, Vespa velutina Lepeletier 1836 (Hym.: Vespidae), in its introduced habitat in Galicia (NW Spain). Insects 2019, 10, 237. [CrossRef] [PubMed]

36. Ghosh, S.; Jung, C.; Meyer-Rochow, V.B. Nutritional value and chemical composition of larvae, pupae, and adults of worker honey bee, Apis mellifera ligustica as a sustainable food source. J. Asia Pac. Èntomol. 2016, 19, 487-495. [CrossRef]

37. Ghosh, S.; Jung, C.; Choi, K.; Choi, H.Y.; Kim, H.W.; Kim, S. Body fat and amino acid composition of a native bumblebee, Bombus ignitus relative to B. terrestris of foreign origin in Korea. J. Apic. 2017, 32, 111-117. [CrossRef]

38. Ghosh, S.; Choi, K.; Kim, S.; Jung, C. Body Compositional Changes of Fatty Acid and Amino Acid from the Queen of Bumblebee, Bombus terrestris during Overwintering. J. Apic. 2017, 32, 11-18. [CrossRef]

39. Ghosh, S.; Sohn, H.-Y.; Pyo, S.-J.; Jensen, A.B.; Meyer-Rochow, V.B.; Jung, C. Nutritional Composition of Apis mellifera Drones from Korea and Denmark as a Potential Sustainable Alternative Food Source: Comparison Between Developmental Stages. Foods 2020, 9, 389. [CrossRef] [PubMed]

40. Tomé, D.; Bos, C. Lysine Requirement through the Human Life Cycle. J. Nutr. 2007, 137, 1642S-1645S. [CrossRef] 
41. Chakravorty, J.; Ghosh, S.; Jung, C.; Meyer-Rochow, V. Nutritional composition of Chondacris rosea and Brachytrupes orientalis: Two common insects used as food by tribes of Arunachal Pradesh, India. J. Asia Pac. Ėntomol. 2014, 17, 407-415. [CrossRef]

42. Ghosh, S.; Lee, S.-M.; Jung, C.; Meyer-Rochow, V. Nutritional composition of five commercial edible insects in South Korea. J. Asia Pac. Èntomol. 2017, 20, 686-694. [CrossRef]

43. Ayieko, M.A.; Kinyuru, J.N.; Ndonǵa, M.F.; Kenji, G.M. Nutritional value and consumption of black ants (Carebara vidua Smith) from the Lake Victoria region in Kenya. Adv. J. Food Sci. Technol. 2012, 4, 39-45.

44. Sihamala, O.; Bhulaidok, S.; Shen, L.R.; Li, D. Lipids and fatty acid composition of dried edible red and black ants. Agric. Sci. China 2010, 9, 1072-1077.

45. Bhulaidok, S.; Sihamala, O.; Shen, L.; Li, D. Nutritional and fatty acid profiles of sun dried edible black ants (Polyrhachis vicina Roger). Majeo Int. J. Sci. Technol. 2010, 4, 101-112.

46. Chakravorty, J.; Ghosh, S.; Megu, K.; Jung, C.; Meyer-Rochow, V. Nutritional and anti-nutritional composition of Oecophylla smaragdina (Hymenoptera: Formicidae) and Odontotermes sp. (Isoptera: Termitidae): Two preferred edible insects of Arunachal Pradesh, India. J. Asia Pac. Èntomol. 2016, 19, 711-720. [CrossRef]

47. Lehtovaara, V.; Valtonen, A.; Sorjonen, J.; Hiltunen, M.; Rutaro, K.; Malinga, G.; Nyeko, P.; Roininen, H. The fatty acid contents of the edible grasshopper Ruspolia differens can be manipulated using artificial diets. J. Insects Food Feed. 2017, 3, 253-262. [CrossRef]

48. Rutaro, K.; Malinga, G.M.; Lehtovaara, V.J.; Opoke, R.; Nyeko, P.; Roininen, H.; Valtonen, A. Fatty acid content and composition in edible Ruspolia differens feeding on mixtures of natural food plants. BMC Res. Notes 2018, 11, 687. [CrossRef]

49. Mensink, R.P. Effects of the individual saturated fatty acids on serum lipids and lipoprotein concentrations. Am. J. Clin. Nutr. 1993, 57, 711S-714S. [CrossRef]

50. Aluko, R.E. Functional Foods and Nutraceuticals; Springer: New York, NY, USA, 2012.

51. Grundy, S.M. Comparison of Monounsaturated Fatty Acids and Carbohydrates for Lowering Plasma Cholesterol. N. Engl. J. Med. 1986, 314, 745-748. [CrossRef] [PubMed]

52. Abeywardena, M.Y.; Patten, G.S. Role of $\omega 3$ long-chain polyunsaturated fatty acids in reducing cardio-metabolic risk factors. Endocr. Metab. Immune Disord. Drug Targets 2011, 11, 232-246. [CrossRef] [PubMed]

53. Bagge, C.N.; Strandhave, C.; Skov, C.M.; Svensson, M.; Schmidt, E.B.; Christensen, J.H. Marine n-3 polyunsaturated fatty acids affect the blood pressure control in patients with newly diagnosed hypertension-A 1-year follow-up study. Nutr. Res. 2017, 38, 71-78. [CrossRef] [PubMed]

54. Cabo, J.; Alonso, R.; Mata, P. Omega-3 fatty acids and blood pressure. Br. J. Nutr. 2012, 107, S195-S200. [CrossRef]

55. Rumpold, B.A.; Schlüter, O.K. Nutritional composition and safety aspects of edible insects. Mol. Nutr. Food Res. 2013, 57, 802-823. [CrossRef]

56. He, F.J.; MacGregor, G.A. Beneficial effects of potassium on human health. Physiol. Plant. 2008, 133, 725-735. [CrossRef]

57. Doyle, M.E.; Glass, K.A. Sodium Reduction and Its Effect on Food Safety, Food Quality, and Human Health. Compr. Rev. Food Sci. Food Saf. 2010, 9, 44-56. [CrossRef]

58. Iwahori, T.; Miura, K.; Ueshima, H. Time to Consider Use of the Sodium-to-Potassium Ratio for Practical Sodium Reduction and Potassium Increase. Nutrients 2017, 9, 700. [CrossRef]

59. Institute of Medicine (US) Standing Committee on the Scientific Evaluation of Dietary Reference Intakes. Dietary Reference Intakes for Calcium, Phosphorus, Magnesium, Vitamin D, and Fluoride; National Academies Press: Washington, DC, USA, 1997.

60. Gennari, C.; Lezama, I.; Lockwood, K.; Bergmann, T. Calcium and vitamin D nutrition and bone disease of the elderly. Public Health Nutr. 2001, 4, 547-559. [CrossRef] [PubMed]

61. Power, M.L.; Heaney, R.P.; Kalkwarf, H.J.; Pitkin, R.M.; Repke, J.T.; Tsang, R.C.; Schulkin, J. The role of calcium in health and disease. Am. J. Obstet. Gynecol. 1999, 181, 1560-1569. [CrossRef]

62. Ramakrishnan, U.; Imhoff-Kunsch, B. Anemia and Iron Deficiency in Developing Countries. In Handbook of Nutrition and Pregnancy; Springer International Publishing: New York, NY, USA, 2008; pp. 337-354.

63. Lutter, C.K. Iron Deficiency in Young Children in Low-Income Countries and New Approaches for Its Prevention. J. Nutr. 2008, 138, 2523-2528. [CrossRef]

64. The Problem: About Iron Deficiency. Available online: http://www.unicef.org/nutrition/23964_iron.html (accessed on 27 August 2019).

65. Gupta, A.; Gadipudi, A. Iron deficiency anaemia in pregnancy: Developed versus developing countries. EMJ Hematol. 2018, 6, 101-109.

66. Aggett, P.J.; Comerford, J.G. Zinc and human health. Nutr. Rev. 1995, 53, S16-S22. [PubMed]

67. Caulfield, L.E.; Black, R.E. Zinc deficiency, In Comparative Quantification of Health Risks: Global and Regional Burden of Disease Attributable to Selected Major Risk Factors; Ezzati, M., Lopez, A.D., Rodgers, A., Murray, C.J.L., Eds.; World Health Organization: Geneva, Switzerland, 2004; Volume 1, pp. 257-279.

68. Maxfield, L.; Crane, J.S. Zinc Deficiency. Available online: https://www.ncbi.nlm.nih.gov/books/NBK493231/ (accessed on 28 August 2019).

69. Wessells, K.R.; Brown, K.H. Estimating the Global Prevalence of Zinc Deficiency: Results Based on Zinc Availability in National Food Supplies and the Prevalence of Stunting. PLoS ONE 2012, 7, e50568. [CrossRef]

70. Meyer-Rochow, V.B. Can insects help to ease the problem of world food shortage? Search 1975, 6, 261-262.

71. Han, R.; Shin, J.T.; Kim, J.; Choi, Y.S.; Kim, Y.W. An overview of the South Korean edible insect food industry: Challenges and future pricing/promotion strategies. Èntomol. Res. 2017, 47, 141-151. [CrossRef] 
72. Kim, T.-K.; Yong, H.I.; Kim, Y.-B.; Kim, H.-W.; Choi, Y.-S. Edible Insects as a Protein Source: A Review of Public Perception, Processing Technology, and Research Trends. Food Sci. Anim. Resour. 2019, 39, 521-540. [CrossRef]

73. Meyer-Rochow, V.B.; Ghosh, S.; Jung, C. Farming of insects for food and feed in South Korea: Tradition and innovation. Berl. Münchener Tierärztliche Wochenschr. 2019, 131, 236-244. [CrossRef] 